\title{
FECHA DEL PRIMER PARTO Y PRODUCTIVIDAD DE VACAS CHAROLAIS EN COAHUILA, MÉXICO ${ }^{1}$
}

\author{
Ramiro López-Trujillo², Roberto García-Elizondo ${ }^{3}$,Fernando Ruiz-Zárate ${ }^{3}$
}

\section{RESUMEN}

Fecha del primer parto y productividad de vacas Charolais en Coahuila, México. El objetivo de este estudio fue evaluar el efecto de la fecha del primer parto de vacas Charolais sobre su eficiencia productiva en un sistema vaca cría del sureste de Coahuila, México. Se analizó una década de información del hato para probar tal efecto. Cada animal ( $\mathrm{n}=201)$ se asignó a uno de dos grupos consecutivos de pariciones de 42 días, conforme a la fecha de su primer parto. Las vacas que parieron temprano perdieron esta característica en partos subsecuentes; la repetibilidad (Ri) de la fecha al parto fue de 0,25 , lo que indica que el mejoramiento de la fertilidad, desechando vacas cuyo primer parto fue tardío, sería modesto. La edad y peso al destete de las crías presentaron tendencias similares $(\mathrm{p} \leq 0,01)$. Las $\mathrm{Ri}$ del peso al destete de las crías y de la eficiencia al destete de la vaca fueron 0,11 y 0,27 , respectivamente. El peso al destete de las vacas $(\mathrm{Ri}=0,66)$ respondió de manera cuadrática al número de parto, pero las que tuvieron el primer parto tardío consistentemente pesaron menos. Los animales cuyo primer parto ocurrió al inicio de la estación de partos, tuvieron mayor eficiencia en su vida productiva, como resultado de su comportamiento en dicho parto. La baja Ri de la fecha al parto indicó que esta variable fue sensible a las prácticas de manejo reproductivo y alimenticio del hato.

\begin{abstract}
\end{abstract}
First calving date and productivity of Charolais cows in Coahuila, Mexico. The aim of the study was to evaluate the effect of first calving date of Charolais cows on their productive efficiency in a cow- calf system in the southeast of Coahuila, Mexico. Ten- year records of the herd were analyzed to test such effect. Each cow $(n=201)$ was assigned to one of the two consecutive calving groups of 42 days each, according to the date of its first calving. Cows calving early lost this trait in subsequent parturitions; calving date repeatability (Ri) was 0.25 , indicating that improvement of herd fertility, discarding cows that first calving was late, would be modest. Weaning age and weight of calves showed similar tendencies $(\mathrm{p} \leq 0.01)$. Ri for calf's weaning weight and cow's weaning efficiency were 0.11 and 0.27 , respectively. Cow's weaning weight $(\mathrm{Ri}=0.66)$ presented a quadratic response to parity number, but late first calving cows consistently weighed less. Cows, that first calving was at the beginning of the calving season, had better productive efficiency as a result of their performance at first calving. . Low calving date Ri indicates that this variable was sensitive to the reproductive and nutritional management of the herd.

Keywords: beef cattle, calving date, productive efficiency.

Palabras clave: bovinos de carne, fecha de parto, eficiencia productiva.

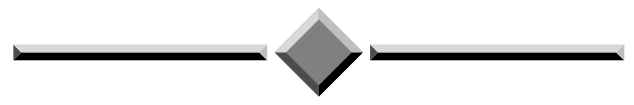

1 Recibido: 24 de setiembre, 2015. Aceptado: 25 de noviembre, 2015. Esta investigación formó parte de la tesis doctoral en zootecnia del segundo autor. Universidad Autónoma Agraria Antonio Narro. Saltillo, Coahuila, México.

2 Universidad Autónoma Agraria Antonio Narro, Departamento de Nutrición y Alimentos. Calzada Antonio Narro 1923, Saltillo, Coah., 25315. México.rlopez@uaaan.mx

3 Universidad Autónoma Agraria Antonio Narro, Departamento de Producción Animal. Calzada Antonio Narro 1923, Saltillo, Coah., 25315. México.robergareli@yahoo.com.mx,frzarat@gmail.com 


\section{INTRODUCCIÓN}

En los hatos de cría de bovinos productores de carne, definir la época y duración del empadre, y por lo tanto de pariciones, es una de las decisiones que determinan su productividad en condiciones de pastoreo extensivo (Grings et al., 2005). En hatos con empadre restringido y fecha única de destete, las vacas más eficientes son las que paren al inicio de la temporada de partos (Pérez et al., 2011; Cushman et al., 2013), ya que destetan becerros más pesados (Funston et al., 2012), tienen más tiempo para reiniciar los ciclos reproductivos (Cushman et al., 2013) e inclusive pueden llegar ciclando al siguiente empadre y, por lo tanto, tener más oportunidades de preñarse al inicio de dicho empadre. Así, las vacas vuelven a parir temprano al año siguiente (Kill et al., 2012) y permanecen más tiempo en el hato (Mousel et al., 2012; Cushman et al., 2013). Por otra parte, las vacas que paren al final de la temporada de partos tienden a volver a parir tarde o no parir al año siguiente y destetan becerros más livianos (Kill et al., 2012).

Por lo anterior, se ha explorado la posibilidad de utilizar la fecha del primer parto como un indicador, temprano y fácil, para medir la productividad de las vacas en uno o dos partos (Bourdon y Brinks, 1983; Marshall et al., 1990; Grings et al., 2005). La fecha del primer parto también se ha propuesto como criterio de selección de vacas jóvenes (vander Westhuizen et al., 2001; Corbet et al., 2006; Bormann y Wilson, 2010). Sin embargo, son escasos los reportes sobre el efecto de la fecha del primer parto en la vida productiva de vacas en condiciones extensivas con empadre restringido (Funston et al., 2012; Cushman et al., 2013).

El objetivo de este estudio fue evaluar el efecto de la fecha del primer parto de vacas Charolais sobre su eficiencia productiva en un sistema vaca - cría del sureste de Coahuila, México.

\section{MATERIALES Y MÉTODOS}

Se analizó una década de registros de bovinos del Rancho Demostrativo Los Ángeles, de la Universidad Autónoma Agraria Antonio Narro. El rancho está ubicado en el suroeste del municipio de Saltillo, Coahuila, México, entre $25^{\circ} 04^{\prime}$ y $25^{\circ} 08^{\prime} \mathrm{N}$ y $100^{\circ} 58^{\prime}$ y $101^{\circ} 03^{\prime} \mathrm{O}$ con altitud promedio de $2250 \mathrm{~m}$. El clima de la región es estepario ( $\mathrm{BS}_{\mathrm{o}} \mathrm{k}$ ”w) con promedios anuales de temperatura de 12 a $18{ }^{\circ} \mathrm{C}$ y precipitación anual de $330 \mathrm{~mm}$, distribuida principalmente entre junio y septiembre (CONAGUA, 2006).

Los registros incluyeron 201 vacas Charolais, con diferente número de registros por animal. Los promedios de las características del hato con el que se trabajó fueron: $39 \pm 3 \mathrm{~kg}$ de peso al nacer de las crías (PNC) y $234 \pm 35 \mathrm{~kg}$ de su peso al destete (PDC), la edad al destete de la cría (EDC) fue $214 \pm 26$ d y su incremento de peso diario predestete (IPC) $0,92 \pm 0,15$ $\mathrm{kg} / \mathrm{d}$; los pesos al parto y al destete de las vacas (PPV y PDV) fueron $503 \pm 50$ y $556 \pm 58 \mathrm{~kg}$, respectivamente; la fecha del parto (FP) y eficiencia de la vaca al destete (EVD=PDC/PDV) fueron: 9 de abril $\pm 27 \mathrm{~d}$ y $0,42 \pm 0,07$, respectivamente.

El rango de edad en las vacas fue de tres (primer parto) a ocho (sexto parto) años y se apacentaron en potreros semiáridos (pastizal mediano abierto, pastizal amacollado y matorral rosetófilo) bajo un esquema de pastoreo rotacional diferido con 15 a 20 ha/UA/año. Todos los años se ofreció un complemento alimenticio de sal, fósforo y minerales traza; en invierno se suministró intramuscularmente vitamina $\mathrm{A}$, y en algunos años se proporcionó $1 \mathrm{~kg} / \mathrm{vaca}$ de excreta de pollo ( $24 \%$ de proteína cruda), durante 60 a 90 días.

El empadre tuvo una duración de 90 días (junio, julio y agosto) utilizando un semental por cada 20 a 30 hembras. Sin embargo, el empadre de las vaquillas inicio quince días antes que el de las vacas. Los partos ocurrieron en primavera (en promedio el 9 de abril \pm 27 días) y el destete en otoño (principios de noviembre). En el hato solo permanecieron las vacas que destetaron un becerro por año.

Se registraron fechas y pesos corporales al parto y destete de vacas y crías; para las vacas se calculó FP y EVD (BIF, 2002; Rogers et al., 2002; MacNeil, 2005) y para las crías edad al destete (EDC) e IPC. Estas variables se agruparon, con base en la fecha del primer parto, en dos periodos consecutivos de 42 días con 436 y 166 observaciones, distribuidas en seis partos.

Para el análisis se usó un modelo de efectos mixtos y observaciones repetidas (partos dentro de vaca):

$$
\mathrm{y}_{\mathrm{ijklm}}=\mu+\beta_{\mathrm{i}}+\gamma_{\mathrm{j}}+\pi_{\mathrm{k}}+\mathrm{v}_{\mathrm{l}(\mathrm{k})}+\eta_{\mathrm{m}}+(\pi \eta)_{\mathrm{km}}+\mathrm{e}_{\mathrm{ijklm}}
$$

donde, $\mathrm{i}, \mathrm{j}, \ldots \mathrm{m}$ representan sexo de la cría, año del parto, grupo de partos, vaca y número del parto; los 
efectos aleatorios se indican con letras itálicas (vaca dentro de grupo de parto y error experimental) y los fijos con griegas (i.e., el resto de los efectos). El patrón de correlaciones entre observaciones se juzgó con el criterio Bayesiano de Schwarz (SAS, 1990; Littell et al., 1998); las matrices de covarianza probadas fueron: simétrica, autoregresiva y no-estructurada, la mejor de ellas se usó para las pruebas estadísticas (efectos principales, interacciones y pruebas de rango múltiple). La repetibilidad (correlación intraclase, $\mathrm{R}_{\mathrm{i}}$ ) se calculó con la matriz simétrica (Lesmeister et al., 1973; Steel y Torrie, 1980).

\section{RESULTADOS Y DISCUSIÓN}

El año del parto y sexo de la cría fueron eficientes para reducir el error experimental. El primero fue significativo $(\mathrm{p} \leq 0,05)$ para todas las variables analizadas y el segundo no fue significativo $(p \geq 0,05)$ para PDV, EDC ni para FP. La discusión de estas dos fuentes de variación se omite; la primera por la complejidad de factores de manejo y climáticos involucrados y la otra, por ser un lugar común.

Subyace en la hipótesis a probar que, en hatos con fecha de destete común dentro del año, la EVD es mayor en las vacas que paren temprano debido a la mayor edad y, por tanto, al mayor peso al destete de sus crías.

Las vacas que parieron temprano, al inicio de su vida productiva, perdieron esta característica en partos subsecuentes ( $\mathrm{FP}=39+36$ (número de parto)-4(número de parto $)^{2}, p \leq 0,01$ y $\left.R^{2}=0,97\right)$, en tanto que vacas con primer parto tardío mantuvieron $(\mathrm{FP}=120 \pm 2)$ este rasgo. A partir del tercer parto los animales se comportaron similarmente $(p \geq 0,05)$. Esta interacción se puede atribuir a que vacas con partos tardíos tienen anestros pospartos más cortos y concepciones más tempranas, como consecuencia de parir en ambiente alimenticio estacional favorable. Pero, en hatos con empadre estacional y eliminación de vacas no gestantes, los animales con partos tardíos tienen menos probabilidad de preñarse por lo reducido del periodo de empadre, lo que repercute negativamente en su vida productiva. Sin embargo, en el presente estudio la proporción de vacas que lograron seis partos consecutivos fue similar para ambos grupos $\left(\mathrm{x}^{2}\right.$, $\mathrm{p} \leq 0,16$; Steel y Torrie, 1980; SAS, 1990).
La repetibilidad de la FP en seis partos consecutivos fue 0,25 . Los valores reportados por Lesmeister et al. (1973) fueron 0,092 y 0,105 (en dos hatos diferentes), por Rege y Famula (1993) 0,23 y por vander Westhuizen et al. (2001) 0,12 . Lo anterior indica que el posible mejoramiento de la fertilidad sería modesto al desechar vacas cuyo primer parto fue tardío, y fecundar vaquillas semanas antes del empadre general no necesariamente es acertado (Funston y Deutscher, 2004), sobre todo en ambientes alimenticios limitados y sin suplementos posparto.

\section{Eficiencia de la vaca al destete}

La EVD (PDC/PDV), disminuyó de diferente manera con el número de parto ( $\mathrm{p} \leq 0,05$; Figura $1 \mathrm{~A})$. Para vacas de primer parto temprano lo determinante fue la disminución del PDC $(\mathrm{r}=0,78, \mathrm{p} \leq 0,01)$, y para las de parto tardío el incremento de PDV ( $\mathrm{r}=-0,44$, $\mathrm{p} \leq 0,01$; Figura 1B), ya que el peso al destete de sus crías fue similar en todos los partos (Figura 2B). La repetibilidad de EVD fue 0,27.

\section{Edad y peso al destete de las crías}

La EDC y PDC $(r=0,45, p \leq 0,01)$ presentaron tendencias similares (Figura 2), la primera fue una imagen invertida de la FP ( $r=-0,79, \mathrm{p} \leq 0,01)$. En los dos primeros partos la EDC fue superior para las vacas con primer parto temprano $(\mathrm{p} \leq 0,05)$; sin embargo, solo en el primero esta diferencia se reflejó $(\mathrm{p} \leq 0,05)$ en el PDC $(255 \pm 2$ vs $214 \pm 3 \mathrm{~kg})$ y consecuentemente en la $\operatorname{EVD}(0,49 \pm 0,005$ vs $0,41 \pm 0,008)$.

La interacción grupo de primer parto por número de parto fue significativa $(\mathrm{p} \leq 0,01)$ para PDC (Figura 2B). Los efectos simples de grupo dentro de parto indicaron que las diferencias se originaron en el primer parto $(255 \pm 2$ vs $214 \pm 3 \mathrm{~kg} ; \mathrm{p} \leq 0,05)$; lo cual coincide con lo reportado por García et al. (1992).

En el otro sentido de los efectos simples, en la Figura 2B se observa que las ventajas y desventajas de los grupos desaparecen con el número de parto $(\mathrm{p} \leq 0,05)$; esto posiblemente debido a que la EDC fue similar a partir del tercer parto $(\mathrm{p} \leq 0,05$; Figura $2 \mathrm{~A})$.

Como la EDC y el periodo de lactancia son magnitudes similares, se pudo inferir que las vacas con primer parto temprano diluyeron la proporción de alimento utilizado para mantenimiento, ya que 


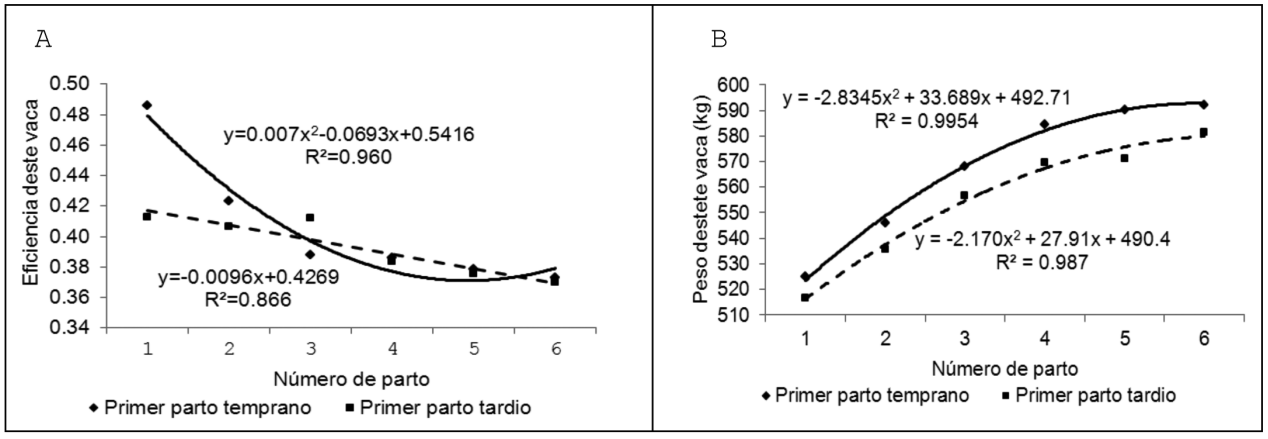

Figura 1. Eficiencia (A) y peso al destete (B) de vacas Charolais apacentando en potreros semiáridos al suroeste de Saltillo, Coahuila, México. 2010.

Figure 1. Efficiency (A) and (B) weaning weight of Charolais cows on arid rangelands in the southwest of Saltillo, Coahuila, Mexico. 2010.

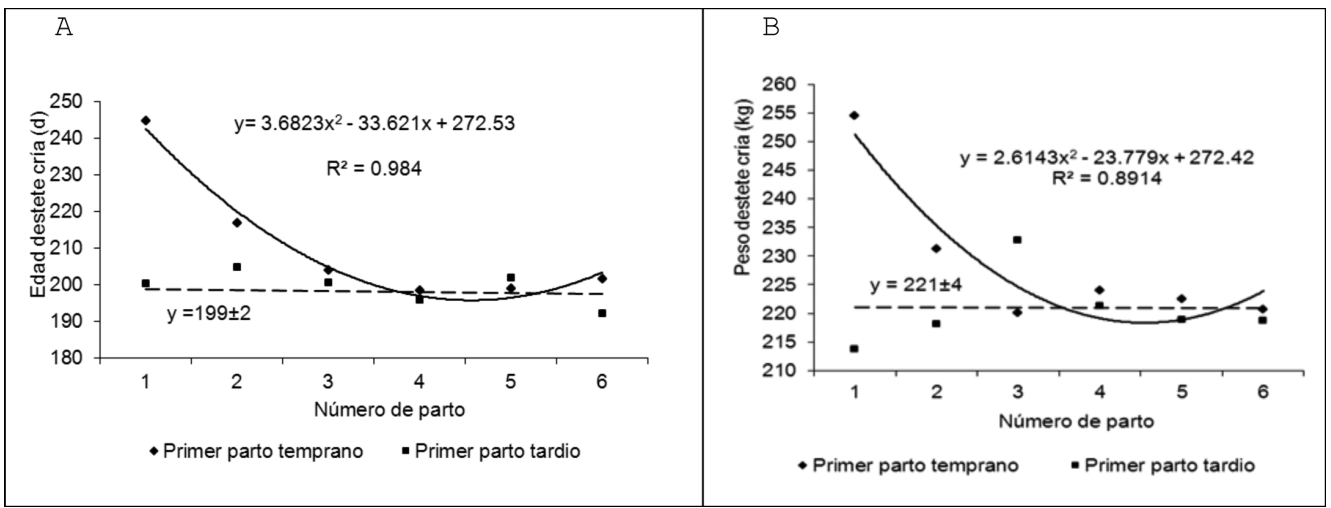

Figura 2. Edad (A) y peso (B) al destete de crías de vacas Charolais apacentando en potreros semiáridos al suroeste de Saltillo, Coahuila, México. 2010.

Figure 2. Age (A) and (B) weaning weight of Charolais cows' calves on arid rangelands in the southwest of Saltillo, Coahuila, Mexico. 2010.

permanecieron más tiempo en su fase productiva, en los dos primeros partos, incrementando así su eficiencia alimenticia.

La repetibilidad, en seis partos consecutivos, de PDC fue de 0,11 . Esta fue pequeña pero comparable a las estimaciones reportadas (Lesmeister et al., 1973).

Sobre el PDC inciden, además de la EDC, el peso al nacer y el incremento en peso predestete de la cría. Las correlaciones simples de PDC con PNC, EDC e IPC fueron $0,23,0,45$ y $0,74(p \leq 0,01)$, respectivamente. Como consecuencia de estas correlaciones, el coeficiente de determinación $\left(\mathrm{R}^{2}\right)$ del IPC con respecto al PDC fue 0,56; al incluir EDC este coeficiente ascendió a 0,98 (forward stepwise regresion; Draper y Smith, 1966). Lo anterior implicó que la importancia del peso de la cría al nacimiento, en la explicación de su peso al destete, fue muy baja; situación que se observó en todos los casos de la interacción de grupos de fechas al primer parto por número de parto. 


\section{Peso al nacimiento de la crías}

Solo los efectos principales en el modelo fueron significativos $(p \leq 0,05)$ para PNC. Las vacas con primer parto temprano tuvieron crías con peso al nacer superior $(40 \pm 0,2$ vs $39 \pm 0,4 \mathrm{~kg}$; $\mathrm{p} \leq 0,05$; diferencia que biológicamente pueda no ser significativa), y los PNC en los primeros y últimos partos fueron similares e inferiores a las de los partos intermedios (Figura 3A).

A diferencia de lo reportado por MacGregor y Casey (2000) y Funston et al. (2012), pero coincidiendo con Marshall et al. (1990) y García et al. (1992), no se observó que las vacas que tuvieron su primer parto temprano hayan parido crías con menor peso. Esta contradicción puede atribuirse a las condiciones alimenticias que preceden al parto. Por otra parte, la tendencia cuadrática del PNC $(\mathrm{p} \geq 0,05)$ sobre número de parto puede deberse al efecto de la evolución de las capacidades fisiológicas de la vaca (Elzo et al., 1987; BIF, 2002; Rogers et al., 2002). La repetibilidad del PNC fue 0,1 .

\section{Incremento diario de peso predestete de las crías}

De los factores analizados, solo el número de parto afectó al IPC ( $\leq 0,05$; Figura 3B). La tasa de crecimiento predestete de las crías mostró la respuesta comúnmente observada: menor en vacas jóvenes y viejas que en adultas (Rogers et al., 2002).

La correlación entre EDC e IPC fue negativa $(-0,24 ; p \leq 0,05)$. Sin embargo, esta relación tuvo un impacto menor sobre el PDC que el de EDC. Por otra parte, la repetibilidad del IPC fue 0,09 .

\section{Peso al destete de las vacas}

El PDV respondió de forma cuadrática al número de parto $(\mathrm{p} \leq 0,05)$; este comportamiento es atribuible al avance en la madurez biológica de las vacas (BIF, 2002; Rogers et al., 2002; Rumph y van Vleck, 2004). Sin embargo, los animales con primer parto tardío consistentemente pesaron menos al destete (Figura 1B). Los puntos de inflexión fueron 5,9 y 6,4 partos para las vacas de primer parto temprano y tardío. Por lo anterior, se podría especular que las vacas cuya primera preñez es tardía son genéticamente de menor peso corporal o que su madurez fisiológica la alcanzan a mayor edad.

El peso al destete de las vacas estuvo correlacionado con su peso al parto $(\mathrm{r}=0,82 ; \mathrm{p} \leq 0,05)$. Esto es un indicio del adecuado nivel alimenticio de los animales entre el parto y el destete, el cual se reflejó tanto en los excelentes PDC e IPC observados (presumiblemente debidos a una alta producción de

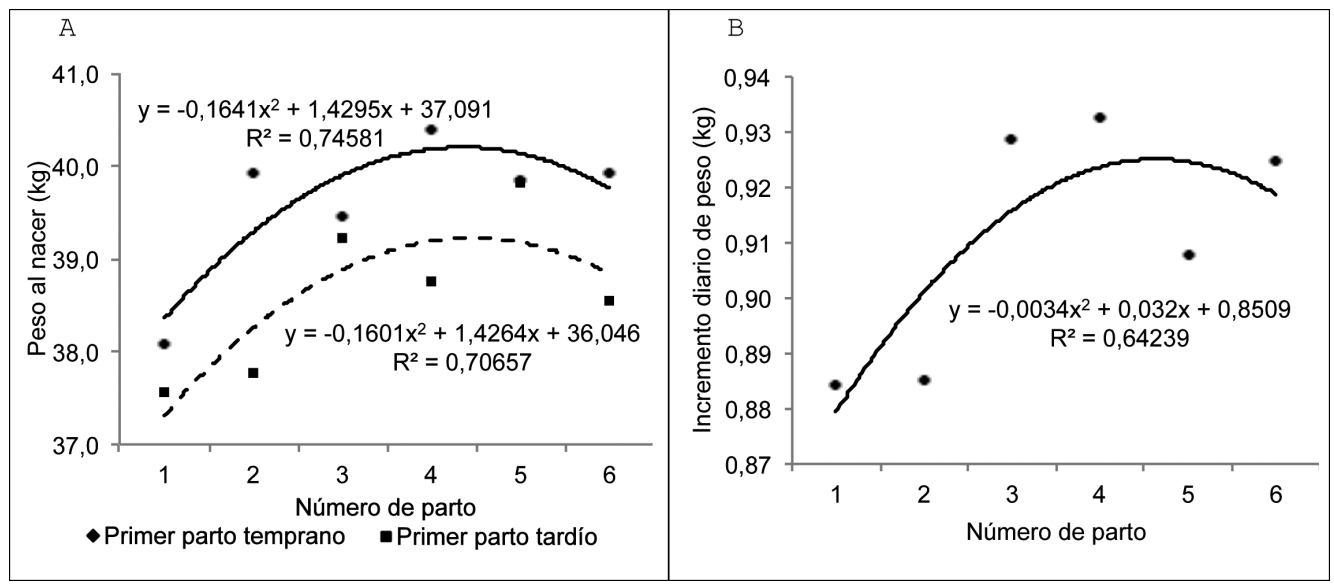

Figura 3. Peso al nacer (A) y (B) incremento diario en peso predestete de crías de vacas Charolais apacentando en potreros semiáridos al suroeste de Saltillo, Coahuila, México. 2010.

Figure 3. Birth weight (A) and (B) daily weight gain preweaning of Charolais cows' calves on arid rangelands in the southwest of Saltillo, Coahuila, Mexico. 2010. 
leche de las vacas; BIF, 2002), como en el buen comportamiento reproductivo del hato (Marshall et al., 1990; García et al., 1992).

El efecto positivo del periodo del primer parto sobre EVD en su vida productiva tuvo sus orígenes en los dos primeros partos. Esto debido a que las vacas con pariciones tempranas destetan crías con mayor edad y, por lo tanto, mayor peso corporal solo en dichos partos, los cuales forman parte del promedio de vida de los animales. La seguridad en esta aseveración radica en: a) las diferencia en peso al nacer de las crías entre grupos de primera parición fue de un orden de magnitud menor y no afectó $(\mathrm{p} \geq 0,05)$ los incrementos en peso predestete de las crías ni el peso al destete de las vacas, b) la fecha de parto de ambos grupos de primera parición, la tendencia fue a converger a partir del tercer parto y c) la edad al destete estuvo inversamente relacionada con la fecha de parto de la vaca $(\mathrm{r}=-0,79)$.

Los valores de repetibilidad calculados fueron: alto para $\operatorname{PDV}(0,66)$, medios para $\operatorname{EVD}(0,27)$ y FP $(0,25)$ y bajos para PDC $(0,11)$, PNC $(0,1)$ e IPC $(0,09)$. Esto implica, en concordancia con MacNeil y Newman (1994), que el mejoramiento genético de los hatos, en base a la fecha del primer parto de las vacas, sería lento. Respecto a los valores de repetibilidad conviene observar que su magnitud depende del número de partos considerados en su cálculo, i.e., a mayor número de partos o distancia entre ellos, sus órdenes de magnitud serán menores.

\section{LITERATURA CITADA}

BIF (Beef Improvement Federation). 2002. Guidelines for uniform beef improvement programs. $8^{\text {th }} \mathrm{ed}$. BIF, The University of Georgia, Athens, GA, USA.

Bormann, J.M., and D.E. Wilson. 2010. Calving day and age at first calving in Angus heifers. J. Anim. Sci. 88:1947-1956.

Bourdon, R.M., and J.S. Brinks. 1983. Calving date versus calving interval as a reproductive measure in beef cattle. J. Anim. Sci. 57:1412-1417.

CONAGUA(Comisión Nacional deAgua). 2006. Estadísticas del agua en México. CONAGUA, Coahuila, MEX.

Corbet, N.J., R.K Shepherd, H.M. Burrow, K.C. Prayaga, J. vander Westhuizen, and D.J. Bosman. 2006 Evaluation of Bonsmara and Belmont Red cattle breeds in South Africa. 2. Genetic parameters for growth and fertility. Austr. J. Exp. Agric. 46:213-223.

Cushman, R.A., L.K. Kill, R.N. Funston, E.M. Mousel, and G.A. Perry. 2013. Heifer calving date positively influences calf weaning weights through six parturitions. J. Anim. Sci. 91:4486-4491.

Draper, N.R., and H. Smith. 1966. Applied regression analysis. John Wiley \& Sons, NY, USA.

Elzo, M.A., R.L. Quass, and E.J. Pollak. 1987. Effects of age-of-dam on weight traits in the Simmental population. J. Anim. Sci. 64:992-1001.

Funston, R.N., and G.H. Deutscher. 2004. Comparison of target breeding weight and bredding date for replacement beef heifers and effects on subsecuent reproduction and calf performance. J. Anim. Sci. 82:3094-3099.

Funston, R.N., J.A. Musgrave, T.L. Meyer, and D.M. Larson. 2012. Effect of calving distribution on beef cattle progeny performance. J. Anim. Sci. 90:51185121.

García, J.A., R. Alberio, M.C. Miquel, M.O. Grondona, J. Carrillo, and G. Schiersmann. 1992. Effect of calving date on lifetime productivity of cows in a wintercalving Aberdeen Angus herd. Anim. Prod. 55:177-184.

Grings, E.E., R.E. Short, K.D. Klement, T.W. Geary, M.D. MacNeil, M.R. Haferkamp, and R.K. Heitschmidt. 2005. Calving system and weaning age effects on cow and preweaning calf performance in the northern great plains. J. Anim. Sci. 83:2671-2683.

Kill, L.K., E.M. Mousel, R.A. Kushman, and G.A. Perry. 2012. Effect of heifer calving date on longevity and life time productivity. J. Dairy Sci. 95:131.

Lesmeister, J.L., P.J. Burfening, and R.L. Blackwell. 1973. Date of first calving in beef cows and subsequent calf production. J. Anim. Sci. 36:1-6.

Littell, R.C., P.R. Henry, and C.B. Ammerman. 1998. Statistical analysis of repeated measures data using SAS procedures. J. Anim. Sci. 76:1216-1231.

MacGregor, R.G., and N.H. Casey. 2000. The effects of maternal calving date and calving interval on growth performance of beef calves. South Afr. J. Anim. Sci. 30:70-76.

MacNeil, M.D. 2005. Genetic evaluation of the ratio of calf weaning weight to cow weight. J. Anim. Sci. 83:794802.

MacNeil, M.D., and S. Newman. 1994. Genetic analysis of calving date in miles city line 1 hereford cattle. J. Anim. Sci. 72:3073-3079. 
Marshall, D.M., W. Minqiang, and B.A. Freking. 1990. Relative calving date of first-calf heifers as related to production efficiency and subsequent reproductive performance. J. Anim. Sci. 68:1812-1817.

Mousel, E.M., R.A. Kushman, G.A. Perry, and L.K. Kill. 2012. Effect of heifer calving date on longevity and life time productivity. In: S. Hermel, editor, Proceedings applied reproduction strategies in beef cattle. Angus Journal. Sioux Falls, SD, USA. p. 23-31.

Pérez, D., R. García, R. López, J.M. Fuentes, y F. Ruíz. F. 2011. Efecto de la fecha de parto sobre características reproductivas de vacas Charolais. Agraria Nueva Época 8:36-43.

Rege, J.E.O., and T.R. Famula. 1993. Factors affecting calving date and its relationship with production traits of Hereford dams. Anim. Prod. 57:385-395.
Rogers, P.L., C.T. Gaskins, and K.A. Johnson. 2002. Cow efficiency and calf growth to weaning of purebred Wagyu and Angus cows with purebred and reciprocally crossed calves. Proc. Western Sect. Amer. Soc. Anim. Sci. 53:33-36.

Rumph, J.M., and L.D. van Vleck. 2004. Age-of-dam adjustment factors for birth and weaning weight records of beef cattle: a review. Genet. Mol. Res. 3:1-17.

SAS. 1990. SAS/Stat Software. $4^{\text {th }}$ ed. SAS Inst., Cary, NC, USA.

Steel, R.G.D., and J.H. Torrie. 1980. Principles and Procedures of Statistics. $2^{\text {nd }}$ ed. McGraw-Hill, NY, USA.

vander Westhuizen, R.R., S.J. Schoeman, G.F. Jordaan, and J.B. van Wyk. 2001. Genetic parameters for reproductive traits in a beef cattle herd estimated using multitrait analysis. South Afr. J. Anim. Sci. 31:41-48. 
